\title{
Neuro-medical complications of fluoride toxicity among populations living in fluorosis endemic region of the Ethiopian Rift Valley
}

Biniyam Alemayehu Ayele ( $\sim$ biniyam.a7@gmail.com )

Addis Abeba University, Department of Neurology https://orcid.org/0000-0002-7955-6030

Yared Mamushet Yifru

Addis Ababa University School of Medicine

Redda Tekle-Haimanot

Addis Ababa University School of Medicine

Tewodros Rango Godebo

Tulane University

Research article

Keywords: Skeletal fluorosis, neurologic complications, Ethiopian Rift Valley

Posted Date: December 23rd, 2019

DOI: https://doi.org/10.21203/rs.2.17675/v2

License: (c) (i) This work is licensed under a Creative Commons Attribution 4.0 International License.

Read Full License 


\section{Abstract}

Background Fluorosis is endemic in many countries of Asia, South America, and Africa. In Africa, the countries located across the Great East African Rift Valley, including Ethiopia are a hotspot for fluorosis. While excessive and chronic exposure to fluoride causes dental and skeletal fluorosis, emerging studies have shown its adverse health effects in cognition, memory, learning and the function of central nervous system. The aim of this study is to assess neurological features of populations chronically exposed to a wide range of fluoride concentrations in drinking water wells in the Ethiopian Rift Valley.Method We conducted a study on 318 individuals living in rural villages located in fluoride endemic areas of the Ethiopian Rift Valley. Drinking water samples were collected from 23 community well sites, and analyzed for fluoride concentrations. Detailed clinical evaluations of skeletal fluorosis, neurologic history, and physical examination were performed in the study participants. Association between different fluoride concentrations and clinical features of fluorosis were done using chi square and crude odds ratio (OR). Results The mean age of the study participants was $28.0 \pm 14.9$ years. Male accounted $55.7 \%$ of the subjects participated. About $80 \%$ of the participants were from the communities who used water from wells containing fluoride concentration $>2 \mathrm{mg} / \mathrm{L}$. The mean fluoride concentration in drinking water samples was $6.8 \pm 4.3 \mathrm{mg} / \mathrm{L}$ (range: 0.3 to $15.5 \mathrm{mg} / \mathrm{L}$ ). Among the neurologic complications, headache, fatigue, and paresthesia accounted for $67 \%, 56.3 \%$, and $37.5 \%$, respectively. Impaired lumbar mobility, impaired squatting, impaired neck mobility, and knocked knee occurred in $22.3 \%, 6.6 \%, 2.2 \%$, and $1.6 \%$, respectively. Impaired lumbar mobility and kyphosis showed statistically significant association with higher fluoride concentration in drinking water $(>2 \mathrm{mg} / \mathrm{L})(\mathrm{P}<0.05)$, while impaired squatting did not $(p=$ 0.9 ) as compared to baseline fluoride concentration $<2 \mathrm{mg} / \mathrm{L}$.Conclusion Our findings strongly suggest that the adverse neurological and medical effects associated with prolonged exposure to elevated concentrations of fluoride in drinking water. We recommend conducting large scale epidemiological study in fluoride endemic areas using controlled population to better understand non-skeletal fluorosis related to neurological and medical complications.

\section{Background}

Fluoride $\left(\mathrm{F}^{-}\right)$is one of the chemicals that commonly found in the environment and known to cause adverse effects in human health, primarily from exposure to naturally contaminated drinking-water sources. According to the World Health Organization (WHO), more than 200 million people worldwide rely on drinking water with fluoride concentrations exceeding the recommended level of $1.5 \mathrm{mg} / \mathrm{L}$ [1]. Fluoride has beneficial effects on teeth often at recommended exposure concentrations of below $1.5 \mathrm{mg} / \mathrm{L}$ in drinking-water [2]. On the contrary, excessive exposure to fluoride in drinking-water, or other sources, can give rise to a number of adverse health effects. These conditions range from mild dental fluorosis to crippling skeletal fluorosis that cause of morbidity, which depends on the fluoride level and duration of exposure time [3].

One of the well-known regions associated with active volcanic activity is located across the East African Rift countries including Ethiopia, Uganda, Kenya and Tanzania. Many of the lakes in the Rift Valley 
system, especially the soda lakes of Elmentaita and Nakuru in Kenya have extremely high concentrations of fluoride, $1640 \mathrm{mg} / \mathrm{L}$ and $2800 \mathrm{mg} / \mathrm{L}$, respectively [4]. In Ethiopia, over 20 million people are living in the Rift Valley areas, which increase their risk of fluorosis, and related complications [5]. In a study in Ethiopia Rift Valley region, from a total 1438 surface and ground water samples, $24.5 \%$ had flouride concentration above $1.5 \mathrm{mg} / \mathrm{L} 囚$ the optimal concentration recommended by World Health Organization [6].

The prevalence of dental and skeletal fluorosis in the Ethiopian Rift Valley was estimated to be $80 \%$ and $45 \%$, respectively $[7,8,9]$. Animal and human studies supported the adverse effect of fluoride on human central nervous system. A study by Yu et al, [10], on human brain tissues from aborted fetuses from endemic fluorosis areas showed fluoride can accumulate in brain tissue and affect the synthesis of certain neurotransmitters and receptors in nerve cells that lead to damages to nerve cells [10]. Waldbott et al. [11], reported prevalence of migraine-like headaches to be $50 \%$ among individuals exposed to chronic fluoride. He analyzed 112 cases from the four different regions around the world for pre-skeletal clinical signs and symptoms of skeletal fluorosis. Accordingly, cervical and lumbar spine arthritic pain accounted for $42 \%$, epigastric pain, nausea and vomiting, accounted $51 \%$, while dermatitis, accounted for $4 \%[11]$.

Unlike previously reported findings, where neurological complications were largely attributed to compressive radioculomyelopathy, a recent experimental study showed the neurotoxic changes in the brain of the rabbits indicated apoptosis of the neurones and neuroglial cells due to fluoride toxicity. The data suggests that there is a direct action of fluoride in high dosage level on the nerve tissue, which is responsible for paralysis, seizure, tremors, and sensory deficits and is indicative of brain dysfunction [12]. High levels of fluoride in drinking water (3-11 ppm) are also known to directly affect the central nervous system and cause intellectual disability and behavioral abnormality without first causing the physical deformities of skeletal fluorosis $[13,14]$.

Toxic level of fluoride in human body causes neurologic disorders, as well as various medical disorders, including, hypothyroidism, polyuria, polydipsia, hearing difficulty, and dyspepsia [15]. Chronic exposure to toxic dose of fluoride in drinking water is associated with different range of symptoms. These include 1) Early signs of skeletal fluorosis such as loss of appetite, nausea, headache, and pallor, 2) Skeletal changes, such as difficulty to touch chest with chin, difficulty of bending forward and touching the toes, and difficulty to sit in squatting position, and 3) physical examination including limitation of movements at the joint (wrist, elbow, shoulder, neck, knees, ankle), bowing of legs, and knocked knee.

The objective of this study is to assess medical and neurological features in populations of the Ethiopian Rift Valley chronically exposed to wide-ranging fluoride concentrations ( 0.3 to $15.5 \mathrm{mg} / \mathrm{L}$ ) in drinking water collected from community-based wells. We also evaluated the associations between variation in $\mathrm{F}^{-}$ in drinking water and different clinical symptoms of skeletal fluorosis.

\section{Methods}




\subsection{Study area}

The study area lies in the Ethiopian Rift Valley, which is part of the Great East African Rift Valley, which bisects the northeastern side of the African continent. The rift floor and the plateaus to the east and west that border the Rift floor have average altitudes of $1600 \mathrm{~m}$ and $2500 \mathrm{~m}$ above sea level (m.a.s.I.), respectively. The climate is semi-arid to arid in the Rift Valley, and the mean annual temperature on the Rift floor exceeds $20^{\circ} \mathrm{C}[16]$.

\subsection{Sampling and measurement of flouride in water samples}

We selected 23 water sampling sites based on previous research data collected on fluoride levels in water sources of the study region, which showed wide variation in exposures to fluoride (ranging from 0.3 to $15.5 \mathrm{mg} / \mathrm{L}$ ) from water extracted from groundwater wells used for drinking and cooking [17-18]. The fluoride concentration was categorized in the following way: $<2 \mathrm{mg} / \mathrm{L},>2-6 \mathrm{mg} / \mathrm{L},>6-10 \mathrm{mg} / \mathrm{L}$, and $>$ $10-15.5 \mathrm{mg} / \mathrm{L}$. These fluoride cut-off values were used in reference to recently published systematic review and meta-analysis aimed to determine fluoride concentration in ground water in Ethiopian Rift Valley [32]. According to this study, the pooled mean concentration of fluoride in ground water of Ethiopian rift valley using Forest plot was $2.8,5.8,8.4$, and $11.2 \mathrm{mg} / \mathrm{L}$. Therefore, we used $<2 \mathrm{mg} / \mathrm{L},>2-6$ $\mathrm{mg} / \mathrm{L}$, > 6-10 mg / L, and > 10-15.5 mg / L cut-off values in order to include all the mean concentration of fluoride in the study area. Water fluoride content was determined using the ion selective electrode (ISE), buffering the standards and water samples using equal volume ratios with a total ionic strength adjustment buffer (TISAB II). This allows optimal analysis of fluoride ion by adjusting the $\mathrm{pH}$ of the solution between 5 and 5.5 , and the ionic strength of the standards and samples to the same values. Calibration standards were prepared from a $100 \mathrm{mg} / \mathrm{L}$ stock solution. The range of electrode calibration slope for a 10-fold change in fluoride concentration was -57 to $-60 \mathrm{mV}$, which is within the acceptable range. The accuracy of ISE fluoride measurements for water standards ranged from $98 \%$ to $102.5 \%$ relative to the standard. The detection limit of the fluoride electrode is $0.02 \mathrm{mg} / \mathrm{L}$.

\subsection{Study population and neurological examination}

The survey questionnaire was conducted in face-to-face interviews by using field enumerators (Ethiopian graduate students and nurses/medical doctors), who were trained on the content of the questionnaire. A total of 318 individuals aged between 10-70 years old were enrolled in selected 23 rural villages that have their respective drinking water wells. Comprehensive physical examination, with emphasis on neurological examination was done for all study participants by certified neurologist. All the examination findings were recorded on structured questionnaire. The neurological assessment includes examination of mental state, cranial nerves, motor, tone, reflex, sensory, and gait. The following physical examinations were done to assess for signs of skeletal fluorosis: ability to touch chest with chin, bending forward and touching the toes, and sitting in squatting position, limitation of movements at the joint (wrist, elbow, shoulder, neck, knees, ankle) and any signs of bowing of legs, and knocked knee.

\subsection{Methodology used to assess clinical signs of anemia in study population}


We have evaluated the study participants for clinical signs of anemia by checking for pallor in the following area: conjunctiva, finger nails and tongue to diagnose anemia. Diagnosing anemia in developing countries such as Ethiopia is difficult because of limited laboratory facilities. However, many studies supported the use of physical examination as a means of diagnosing anemia in resource limited settings [29-30].

\subsection{Statistical analysis}

Demographic data, signs and symptoms of skeletal fluorosis, medical and neurological complications and fluoride exposure variables were first described by their quartiles, means, and standard deviation. Association between different level of flouride concentrations and different variables were done using chi square, adjusted odds ratio (OR) and $p$ value was set at $<0.05$ as statistically significant.

\section{Results}

\subsection{Frequency distribution of socio-demography, fluoride and clinical features.}

The age of our study participants ranged between 10 to 70 years, with a mean age of $28.0 \pm 14.9$ years. Two-hundred two (63.5\%) of our study participants were between the age 15 and 44 years. A little more than half of the study participants $(55.7 \%)$ were males. The mean water flouride level was $6.8 \pm 4.3 \mathrm{mg} / \mathrm{L}$, out of 318 study participants, $20.1 \%$ had water fluoride $<2 \mathrm{mg} / \mathrm{L}$, while $51.6 \%$ had fluoride concentration between 6-16 mg/L [Table 1]. We screened the study participants for pre-skeletal features of fluorosis. Out of 318 participants, $158(49.7 \%)$ had clinical signs of anemia, evidenced by pallor on physical examination. Loss of appetite, constipations, and nausea were reported in $48.1 \%, 45.3 \%$ and $28.9 \%$, respectively. Excessive thirst and urination reported by $6.6 \%$ of study participants [Table 1].

Prevalence of clinical signs related to skeletal fluorosis was evaluated among the study participants, $71(22.3 \%)$ had impaired lumbar mobility, 21 (6.6\%) had impaired squatting, 18(5.7\%) had bow legs, $7(2.2 \%)$ had impaired neck mobility, $6(1.9 \%)$ had kyphosis and 5(1.6\%) had knocked knee [Table 1]. Neurologic signs and symptoms related to chronic fluoride toxicity was evaluated among our study participants. Sixty seven percent $(n=213)$ of participants reported that they are suffering from headache. Thirteen $(4.1 \%)$ of our study participants had a rigid posture and bended at their neck, while $3(0.9 \%)$ of the participants walk with stick support. Hundred-ninety $(37.5 \%)$ reported paresthesia of extremities, while urinary incontinence and muscle atrophy were observed in $2(0.6 \%)$ and $6(1.8 \%)$, respectively [Table 1 ].

\section{Table 1: Frequency distribution of fluoride, demography and clinical features}




\begin{tabular}{|c|c|c|c|}
\hline \multicolumn{4}{|c|}{ A) Frequency of socio-demographic variables and distributions of fluoride } \\
\hline & & Frequency & Percent \\
\hline \multirow[t]{4}{*}{ Fluoride level } & $<2 \mathrm{mg} / \mathrm{l}$ & 64 & 20.1 \\
\hline & $\geq 2-6 \mathrm{mg} / \mathrm{l}$ & 90 & 28.3 \\
\hline & $\geq 6-10 \mathrm{mg} / \mathrm{l}$ & 87 & 27.4 \\
\hline & $\geq 10-16 \mathrm{mg} / \mathrm{l}$ & & 24.2 \\
\hline \multirow[t]{5}{*}{ Age group } & $<15$ & 67 & 21.1 \\
\hline & $\geq 15-24$ & 103 & 32.4 \\
\hline & $\geq 25-34$ & 44 & 13.8 \\
\hline & $\geq 35-44$ & 55 & 17.3 \\
\hline & $\geq 45$ & 49 & 15.4 \\
\hline \multirow{2}{*}{ Gender } & Male & 177 & 55.7 \\
\hline & Female & 141 & 44.3 \\
\hline \multicolumn{4}{|c|}{ B) Frequency of medical complications in study participants } \\
\hline \multirow{2}{*}{ Loss of appetite } & Yes & 153 & 48.1 \\
\hline & No & 165 & 51.9 \\
\hline \multirow{2}{*}{ Nausea } & Yes & 92 & 28.9 \\
\hline & No & 226 & 71.1 \\
\hline \multirow[t]{2}{*}{ Constipation } & Yes & 144 & 45.3 \\
\hline & No & 174 & 54.7 \\
\hline \multirow[t]{2}{*}{ Fatigue } & Yes & 179 & 56.3 \\
\hline & No & 139 & 43.7 \\
\hline \multirow[t]{2}{*}{ Clinical signs of Anemia } & Yes & 158 & 49.7 \\
\hline & No & 160 & 50.3 \\
\hline \multirow[t]{2}{*}{ Excess thirst and urination } & Yes & 21 & 6.6 \\
\hline & No & 297 & 93.4 \\
\hline \multicolumn{4}{|c|}{ C) Frequency distribution of clinical signs of skeletal fluorosis } \\
\hline \multirow[t]{2}{*}{ Impaired lumbar mobility } & Yes & 71 & 22.3 \\
\hline & No & 247 & 77.7 \\
\hline \multirow[t]{2}{*}{ Impaired neck mobility } & Yes & 7 & 2.2 \\
\hline & No & 311 & 97.8 \\
\hline \multirow[t]{2}{*}{ Impaired squatting } & Yes & 21 & 6.6 \\
\hline & No & 297 & 93.4 \\
\hline \multirow[t]{2}{*}{ Knocked knee } & Yes & 5 & 1.6 \\
\hline & No & 313 & 98.4 \\
\hline \multirow[t]{2}{*}{ Bow legs } & Yes & 18 & 5.7 \\
\hline & No & 300 & 94.3 \\
\hline \multirow[t]{2}{*}{ kyphosis } & Yes & 6 & 1.9 \\
\hline & No & 312 & 98.1 \\
\hline \multicolumn{4}{|c|}{ D) Frequency of neurological complications among study participants } \\
\hline \multirow[t]{2}{*}{ Headache } & Yes & 213 & 67.0 \\
\hline & No & 105 & 33.0 \\
\hline \multirow[t]{2}{*}{ Paresthesia of extremities } & Yes & 119 & 37.5 \\
\hline & No & 199 & 62.5 \\
\hline \multirow[t]{2}{*}{ Urinary incontinence } & Yes & 2 & 0.6 \\
\hline & No & 316 & 99.4 \\
\hline \multirow[t]{2}{*}{ Walking with one stick } & Yes & 3 & 0.9 \\
\hline & No & 315 & 99.1 \\
\hline Rigid posture and bending at neck spine & Yes & 13 & 4.1 \\
\hline
\end{tabular}




\begin{tabular}{|l|c|c|c|} 
& No & 305 & 95.9 \\
\hline Muscle atrophy & Yes & 6 & 1.8 \\
& No & 313 & 98.2 \\
\hline
\end{tabular}

\subsection{Association between fluoride concentrations and headache symptom}

We evaluated association between wide ranges of fluoride concentrations in drinking water and headache symptom. Higher concentration of fluoride in drinking water ( $>2 \mathrm{mg} / \mathrm{L}$ ) had statistically significant association with headache $(p<0.05)$ [Table 2], while lower concentration of fluoride $(<2 \mathrm{mg} / \mathrm{L})$ did not show statistically significant association. This suggested that headache symptom is more common among study participants who are exposed to higher concentration of fluoride in drinking water. Moreover, those individuals with fluoride exposure in drinking water between 10-15.5 mg/L are 2 times more vulnerable to develop headache than the baseline exposure ( $<2 \mathrm{mg} / \mathrm{L})$, [Crude OR $(95 \%$ of $\mathrm{Cl})$, 3.52(1.67-7.39)] [Table 2].

Table 2: Association between fluoride concentration and headache

\begin{tabular}{|r|c|c|c|}
\hline & \multicolumn{2}{|c|}{ Headache } & \multirow{2}{*}{$\begin{array}{c}\text { Crude OR } \\
\text { (95\% of CI) }\end{array}$} \\
\cline { 2 - 3 } Fluoride level & Yes (\%) & No (\%) & \\
& $28(43.8)$ & $36(56.2)$ & 1.00 \\
$<2 \mathrm{mg} / \mathrm{L}$ & $61(67.8)$ & $29(32.2)$ & $2.86(1.42-5.74) * *$ \\
$2-6 \mathrm{mg} / \mathrm{L}$ & $67(77.0)$ & $20(23.0)$ & $5.03(2.38-10.6) * *$ \\
$6-10 \mathrm{mg} / \mathrm{L}$ & $57(74.0)$ & $20(26.0)$ & $3.52(1.67-7.39)^{* *}$ \\
$10-15.5 \mathrm{mg} / \mathrm{L}$ & & & \\
\hline
\end{tabular}

$* *=p<0.05$

Paresthesia of extremities showed statistically significant agreement with higher concentration of fluoride $(p=0.03)$. Moreover, signs of crippling neuroflouorosis, such as walking with one stick and rigid posture and bending at neck spine also showed statistically significant association with higher concentration of fluoride in drinking water $(p<0.05)$ [Table 3]. Study participants who drinks water containing fluoride concentration between $>10-15.5 \mathrm{mg} / \mathrm{L}$ were ten times more prone to develop rigid posture and bending at neck spine compared to individuals who are exposed to low concentration of fluoride in drinking water ( $2 \mathrm{mg} / \mathrm{L}$ ) [Table 3]. We evaluated association between different fluoride concentrations and some of the clinical signs of skeletal fluorosis such as impaired lumbar mobility and kyphosis, which showed statistically significant association with higher fluoride concentration in drinking water ( $>2 \mathrm{mg} / \mathrm{L})(p=0.001, p=0.01$, respectively). While impaired squatting did not $(p=0.9)$ [Table 3]. Only those individuals exposed to drinking water containing fluoride concentration $>6 \mathrm{mg} / \mathrm{L}$ had kyphosis compared to those exposed to fluoride concentration $<6 \mathrm{mg} / \mathrm{L}$ [Table 3]. Fluoride concentration $>2 \mathrm{mg} / \mathrm{L}$ was significantly associated with loss of appetite, nausea and constipation $(p=0.001, p=0.02, p=0.001$, respectively), but not with clinical signs of anemia $(p=0.86)$. Among $49.7 \%$ participants who had clinical 
signs of anemia, only $22.4 \%$ used water source containing fluoride concentration $<2 \mathrm{mg} / \mathrm{L}$, whereas $81.6 \%$ of them used water wells containing flouride concentration $>2 \mathrm{mg} / \mathrm{L}$ [Table 3].

Table 3: Association between fluoride concentration and complication of skeletal fluorosis

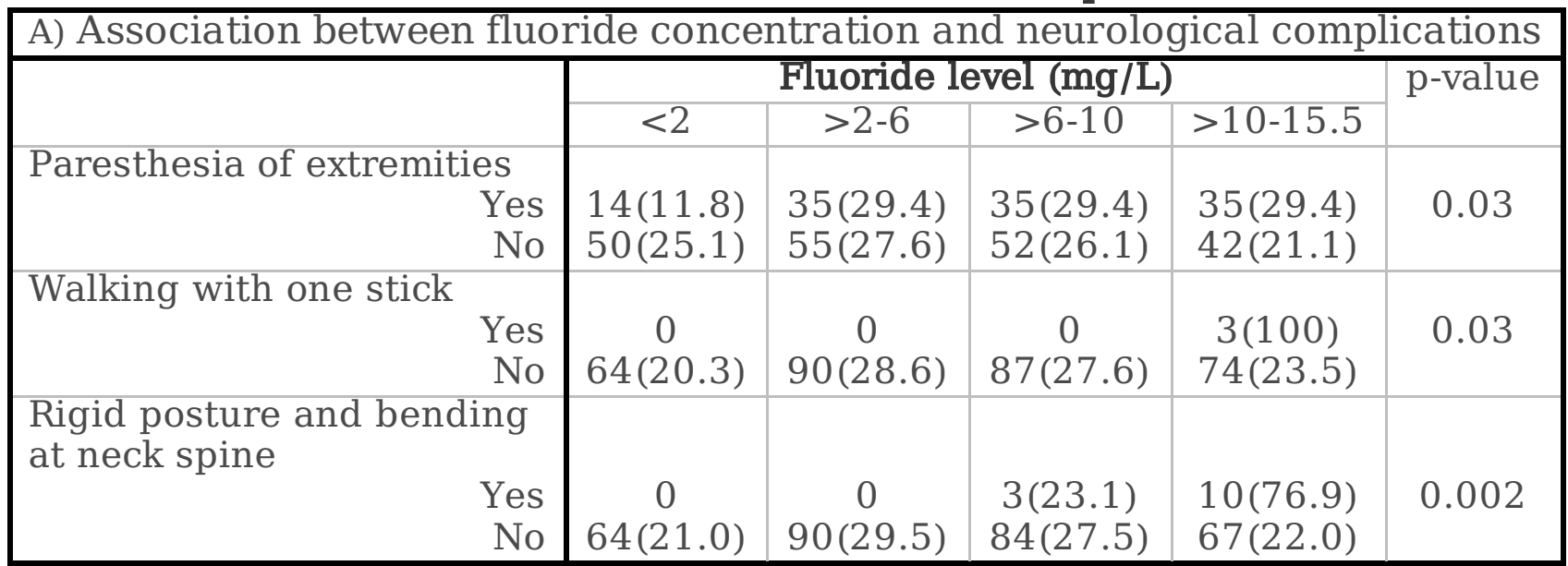

\begin{tabular}{|c|c|c|c|c|c|}
\hline \multirow{2}{*}{\begin{tabular}{|l|} 
B) Association between flour \\
\end{tabular}} & \multicolumn{5}{|c|}{ ation and signs of skeletal fluorosis } \\
\hline & & Fluoride & evel mg/L & & p-value \\
\hline \multirow{2}{*}{ Impaired lumbar mobility } & $<2$ & $>2-6$ & $>6-10$ & $>10-15.5$ & \\
\hline & $27(38.0)$ & $16(22.5)$ & $7(9.9)$ & $21(29.6)$ & 0.001 \\
\hline No & $37(15.0)$ & $74(30.0)$ & $80(32.4)$ & $56(22.7)$ & \\
\hline \multicolumn{5}{|l|}{ Impaired squatting } & \\
\hline \multirow{3}{*}{ kyphosis } & $3(14.3)$ & $6(28.6)$ & $6(28.6)$ & $6(28.6)$ & 0.90 \\
\hline & & & & & \\
\hline & $\begin{array}{c}0 \\
64(20.5)\end{array}$ & $\begin{array}{c}0 \\
90(28.8)\end{array}$ & $\begin{array}{c}1(16.7) \\
86(27.6)\end{array}$ & $\begin{array}{c}5(83.3) \\
72(23.1)\end{array}$ & 0.01 \\
\hline \multicolumn{6}{|c|}{ C) Association between flouride concentration and pre-skeletal signs and symptoms } \\
\hline \multirow{3}{*}{ Loss of appetite } & $<2$ & $\begin{array}{l}\text { Fluoride } \\
>2-6\end{array}$ & $\begin{array}{l}\text { evel } \mathrm{mg} / \mathrm{L} \\
>6-10\end{array}$ & $>10-15.5$ & p-value \\
\hline & $17(11.1)$ & $46(30.1)$ & $48(23.6)$ & $42(27.5)$ & 0.001 \\
\hline & $47(28.5)$ & $44(26.7)$ & $39(23.6)$ & $35(21.2)$ & \\
\hline Nausea & $\begin{array}{c}9(9.8) \\
55(24.3)\end{array}$ & $\begin{array}{l}33(35.9) \\
57(25.2)\end{array}$ & $\begin{array}{l}26(28.3) \\
61(27.0)\end{array}$ & $\begin{array}{l}24(26.1) \\
53(23.5)\end{array}$ & 0.02 \\
\hline \multirow[t]{2}{*}{ Constipation } & $14(9.7)$ & $48(33.3)$ & $47(32.6)$ & $35(24.3)$ & 0.001 \\
\hline & $50(28.7)$ & $42(24.1)$ & $40(23.0)$ & $42(24.1)$ & \\
\hline Clinical signs of Anemia & $\begin{array}{l}29(18.4) \\
35(21.9)\end{array}$ & $\begin{array}{l}47(29.7) \\
43(26.9)\end{array}$ & $\begin{array}{l}43(27.2) \\
44(27.5)\end{array}$ & $\begin{array}{l}39(24.7) \\
38(23.8)\end{array}$ & 0.86 \\
\hline
\end{tabular}

\section{Discussion}

This study is part of a cohort of individuals who are part of a study initiated in Ethiopian Rift Valley with the aim of understanding skeletal and non-skeletal complications of chronic fluoride exposure. The first case of neurological complications of severe fluoride toxicity was reported in Ethiopia 45 -years back by 
Lester, et al, 1974 [19], who reported a case of fluoride myelopathy. Since then population-based studies in the Ethiopian Rift Valley were focused on dental, skeletal, and a few on neurological complications of chronic fluoride intoxication $[17,18,20]$. The mean age of our study participant was $28.0 \pm 14.9$ (range: 10-70 years) and men-to-women ratio was 1.2:1. The mean fluoride concentration in water samples was $6.8 \pm 4.3 \mathrm{mg} / \mathrm{L}$, which is 4.5 times the WHO recommended level [1]. Only $20 \%$ of water samples had fluoride concentration below $2 \mathrm{mg} / \mathrm{L}$. In the previous work, we found statistically significant association between fluoride in drinking water and in urine [27], indicating that fluoride in drinking water is the main source of fluoride exposure in the study region.

Clinical signs of anemia based on evidences of pallor, were observed in close to half of our study participants, which are consistent with study reported by Erdal et, al, (2005), which revealed that the rate of anemia in children living in the fluoride endemic region was 2.4 times greater than children living in non-fluoride endemic regions [21]. Moreover, study done in Malawi reported: pallor of the conjunctiva, tongue, palm or nail beds was $66 \%$ sensitive and $68 \%$ specific in distinguishing children with moderate anemia (hemoglobin concentration, $5-8 \mathrm{~g} / \mathrm{dl}$ ) and $93 \%$ sensitive and $57 \%$ specific in distinguishing those with severe anemia (hemoglobin concentration, $<5 \mathrm{~g} / \mathrm{dl}$ ), even without laboratory support, which is often unavailable in rural Africa [31].

It is well documented that different gastrointestinal (GI) symptoms of $\mathrm{Gl}$ irritation, including nausea, loss of appetite and abdominal pain is common in endemic fluorosis with populations chronically exposed to higher concentrations of fluoride $[22,23]$. This is consistent with our study findings that showed loss of appetite, constipations and nausea were reported in $48.1 \%, 45.3 \%$ and $28.9 \%$, respectively [Table 1 ]. Loss of appetite, constipation and nausea had statistically significant association with higher fluoride concentration $(p<0.05)$ [Table 3].

According to study done by Assefa et al, (2004) among retired employees of wonji-shoa sugar estate in Ethiopia, clinical and radiological prevalence of skeletal fluorosis was found to be $20 \%$ and $70 \%$, respectively [24]. The authors reported impaired squatting in 39\%, impaired neck mobility in $29 \%$ and impaired lumbar mobility in $40.2 \%$ of the subjects [24]. Compared to their study, our study showed lower prevalence of clinical signs of skeletal fluorosis. This is likely because their study participants mean age was 55-years and they only selected individuals having signs and symptoms of skeletal fluorosis, which likely increased the prevalence of skeletal fluorosis. Among clinical signs of skeletal fluorosis, impaired lumbar mobility and kyphosis showed statistically significant) association with higher concentrations of fluoride $(p<0.005$, while impaired squinting did not $(p<0.86)$ [Table 3].

The involvement of the nervous system in skeletal fluorosis was reported in India as early as 1937 and skeletal fluorosis is associated with neurologic complication in 3-10\% [25, 28]. In Ethiopia, neurological complications of chronic fluoride toxicity had a pattern of radiculo-myelopathies in $80 \%$ of individuals suffering from skeletal fluorosis, in which $66 \%$ involves cervical region [20]. Most of previously reported studies on fluoride toxicity largely attribute to neurological complications of chronic fluoride intoxication to mechanical compression of the spinal cord and nerve roots by skeletal fluorosis, rather than direct 
neurotoxic effect of higher fluoride exposure [26]. However, a number of recent publication reported, high levels of fluoride in drinking water (3-11 ppm) are known to affect the central nervous system and can cause intellectual disability and behavioral abnormality without first causing the physical deformities of skeletal fluorosis [14,15].

We observed higher prevalence of headache disorders (67\%) among our participants. Our finding is consistent with a study reported by Waldbott et al (1998), where $50 \%$ of 112 cases of skeletal fluorosis complained of headache [11]. We also found statistically significant association between headache and higher concentration of fluoride in drinking water compared to low fluoride concentration [Table 2]. We found $37.5 \%$ of our study participants reported paresthesia of extremities, which is in line with study done in India were some of their patients having skeletal fluorosis reported paresthesia [11]. Evidences of crippling neuroflourosis (walking with one stick and rigid posture and bending at neck spine) were observed in 13 (4\%) study a participant, likely indicating advanced skeletal and neurological complications of fluoride toxicity often occurs in older patients after decades of exposure to high fluoride water. Signs of rippling neuroflourosis showed statistically significant association with higher concentration of fluoride in drinking water [Table 3]. We have identified the following limitations to our study: absences of controlled group for comparison, relatively small sample size compared to total number of people exposed to toxic dose of fluoride, and failure to use standard laboratory measuring methods, eg. not using hemoglobin measurements while assessing anemia.

\section{Conclusions}

Our findings strongly suggest that the adverse neurological and medical effects associated with prolonged exposure to elevated concentrations of fluoride in drinking water. We recommend conducting large scale epidemiological study in fluoride endemic areas using controlled population to better understand non-skeletal fluorosis related to neurological and medical complications.

\section{List Of Abbreviations}

F-: Fluoride, ERV: Ethiopian Rift Valley, Mg/L: Milligram per liter, WHO: World Health Organization, GI: Gastrointestinal, PPM: Parts per million (ppm)

\section{Declarations}

\section{Ethics approval and consent to participate:}

The study received ethical approval from the Institutional Review Board (IRB) at Tulane University (Protocol No. 2018-043) and locally from the National Research Ethics Review Committee (NRERC) (reference no. MoSHE/144/1096/19). All subjects provided written consent, and parents/guardians gave permission for children to participate in addition to children giving their own assent. 
All authors agreed on the decision to publish this manuscript. Participants consent for publication is not applicable.

\section{Availability of data and materials:}

All data sets on which the conclusions of the manuscript rely are available as spread sheets documents and available from the corresponding author on reasonable request from the journal editors.

\section{Competing interests:}

The authors declare that they have no competing interests.

\section{Funding:}

This is part of an ongoing cohort study in the Ethiopia Rift Valley with a long-term goal of understanding the health impacts of fluoride in teeth, cartilage, joint, and bone mineralized tissues and associated neurologic complications of fluoride related health problems in children and adults. We are immensely grateful for the funding from the NIEHS's career development grant (K99/R00 ES023472).

\section{Authors Contributions:}

Biniyam Alemayehu, Tewodros Rango Godebo: Design of study concept, conducted the field work, analytical data analysis and interpretation, wrote the manuscript. Redda Tekle-Haimanot, Yared Mamushet Yifru: Design of study concept, field work assistance, critical revision of the manuscript for important intellectual content.

Acknowledgements: We thank all the children and parents who participated in this study, and the local water bureaus for their help in recruiting them as well as guiding us during the field work. The content expressed in this paper is the responsibility of the authors and does not necessarily reflect the official views of the $\mathrm{NIH}$.

Authors' information: BA is an assistant professor of Neurology at department of Neurology, College of Health Sciences Addis Ababa University. He is actively involved in clinical practice and researches in field of neurosciences. YM is an assistant professor of Neurology at department of Neurology, College of Health Sciences, Addis Ababa University. He is actively involved in clinical practice and researches in field of neurosciences. RT is a professor Emeritus at Faculty of Medicine, Addis Ababa University. He is pioneer researcher in field of neurosciences in Ethiopia. He published more than 100 high quality original research works. TR is an assistant professor at department of Global Environmental Health Sciences, School of Public Health and Tropical Medicine, Tulane University. He is actively engaged in fluoride related researches in different countries. He published number of high quality original articles.

\section{References}


1. World Health Organization (WHO), "Guidelines for Drinking Water Quality," 1st Addendum to Vol. 1 Recommendations, 3rd Edition, World Health Organization, Geneva, 2006, p. 595.

2. Tekle-Haimanot R., Fekadu A., Bushra B. Endemic fluorosis in the Ethiopian Rift Valley. Tropical and Geographical Medicine. 1987, 39:209-217.

3. World Health Organization (WHO). Fluoride in Drinking-water by J. Fawell, K. Bailey, J. Chilton, E. Dahi, L. Fewtrell and Y. Magara. ISBN: 1900222965.2006. IWA Publishing, London, UK.

4. Nair, K.R, Manji, F., Gitonga, J.N., The occurrence and distribution of fluoride in ground waters of Kenya. In: Challenges in African Hydrology and Water Resources, Proceedings of the Harare Symposium, IAHS Publ. 1984, 144, 75-86.

5. Excessive flouride concentration in the Ethiopian rift and the flowered project, $1^{\text {st }}$ Regional Workshop, 1 st General Assembly and $2^{\text {nd }}$ Steering Committee Meeting, conference paper, Arusha, Tanzania, 2017.

6. Tekle-Haimanot R., Melaku Z., Kloos H., Reimann C. , Fantaye W., Zerihun L.,Bjorvatn K., "The Geographical Distribution of Florid Surface and Groundwater in Ethiopia with an Emphasis on the Rift Valley," Science of the Total Environment, Vol. 367, No. 1, 2005, pp. 182-190. http://dx.doi.org/10.1016/j.scitotenv.2005.11.003.

7. Olsson B., "Dental Findings in High Fluoride Areas of Ethiopia," Community Dental and Oral Epidemiology, Vol. 7, 1979, pp. 51-56. http://dx.doi.org/10.1111/j.1600-0528.1979.tb01185.

8. Tekle-Haimanot R., Gebeyehu H., Chronic Alcohol Consumption and the Development of Skeletal Fluorosis in a Fluoride Endemic Area of the Ethiopian Rift Valley, Journal of Water Resource and Protection, 2014, 6, 149-155. doi.org/10.4236/jwarp.2014.62020.

9. Wondwossen F., Astrom A. N. , Bardsen A., Bjorvatn K., "The Relationship between Dental Caries and Dental Fluorosis in Areas with Moderate- and High-Fluoride Drinking Water in Ethiopia," Community Dent oral Epidemiology, Vol. 32, 2004, pp. 337-344.

10. Yu Y., Dong W., Zhang, Xiao L., Huang L., Neurotransmitter and receptor changes in the brains of fetuses from areas of endemic fluorosis, Translated research report Fluoride, 2008, 41(2)134-138.

11. Waldbott G.L., the Preskeletal Phase of Chronic Fluoride Intoxication, 1998, Fluoride, 31:1, 13-20

12. Santosh K.S., Sujita P. , Mahesh C.S.,, Effect of fluoride on brain of albino-rabbit - An experimental study, International Journal of Applied Research 2017; 3(3): 818-821.

13. Shan Guan C.M. The non-skeletal lesions of endemic fluorosis. Chin J Intern Med 1982; 21:217-9.

14. Ding L.I. The nervous system complications of chronic fluorosis. Chin J Endemiol 1983; 2:97-8.

15. National Research Council. Fluoride in Drinking Water: A Scientific Review of EPA's Standards. 2006, Washington, DC: The National Academies Press., https://doi.org/10.17226/11571.

16. Ethiopian mapping authority. National atlas of Ethiopia. Addis Ababa: Ethiopian mapping authority; 1988.

17. Rango, T., Kravchenko, J., Atlaw, B., McCornick, P.G., Jeuland, M.A., Merola, B., Vengosh, A., 2012. Groundwater quality and its health impact: an assessment of dental fluorosis in rural inhabitants of 
the main Ethiopian Rift. Environ. Int. 43, 37-47.

18. Rango T, Vengosh A, Dwyer G, Bianchini G. 2013. Mobilization of arsenic and other naturally occurring contaminants in groundwater of the Main Ethiopian Rift aquifers. Water Research Journal; 47, 5801-5818.

19. Lester F. Fluoride myelopathy. Ethiopian MedicalJournal, 1974, 12:39-49.

20. Tekle-Haimanot R., Neurological Complications of Endemic Skeletal Fluorosis, with Special Emphasis on Radiculo-Myelopathy, Paraplegia J 28 (1990) 244-251.

21. Erdal E., Mustafa O., Ethem F. M., Duran C., Fluorosis and its hematological effects, Toxicology and Industrial Health 2005; 21: 255/258, 10.1191/0748233705th236oa.

22. Gupta, I.P., Das T.K., Susheela A.K., Dasarathy S., Tandon R.K. Fluoride as a possible etiological factor in non-ulcer dyspepsia. J. Gastroenterol. Hepatol. 1992, 7(4):355-359.

23. Susheela, A.K., Kumar A., Bhatnagar M., Bahadur R. Prevalence of endemic fluorosis with gastrointestinal manifestations in people living in some North-Indian villages. Fluoride. 1993, 26(2):97-104

24. Assefa G., Shifera G, Melaku Z., Tekle- Haimanot, Clinical and radiological prevalence of skeletal fluorosis among retired employees of wonji-shoa sugar estate in Ethiopia, East African Medical Journal Vol. 81 No. 12, 20114 DOl: 10.4314/eamj.v81i12.9250.

25. Shortt H.E., Mcrobert G.R., Barnard T.W., Nayyar A.M. Endemic fluorosis in Madras Presidency. Indian Journal of Medical Research. 1937, 25:553-568.

26. Raja R., Neurology of endemic skeletal fluorosis, Neurology India, 2009, 57:1:7-12.

27. Tewodros R., Avner V. , Marc J. , Gary M.M. ,Tekle-Haimanot R. , Biomarkers of chronic fluoride exposure in groundwater in a highly exposed population, Science of the Total Environment, 596-597 (2017) 1-11.

28. Teotia M., Teotis S.PS., Kumar K.B. Endemic skeletal fluorosis. Arch Dis Child, 1971. 46:686-91.

29. Strobach R.S., the value of the physical examination in the diagnosis of anemia. Correlation of the physical findings and the hemoglobin concentration. Archives of internal medicine, 1988, 148: 831832. 13.

30. Nardone D.A., usefulness of physical examination in detecting the presence or absence of anemia. Archives of internal medicine, 1990, 150: 201-204.

31. Luby S.P., Kazembe P.N., Redd S.C., using clinical signs to diagnose anemia in African children, Bulletin of the World Health Organization, 1995, 73 (4): 477-482.

32. Habtamu D. , Abebe B, Zewdu A., Addisu M, Fluoride concentration in ground water and prevalence of dental fluorosis in Ethiopian Rift Valley: systematic review and meta-analysis, BMC Public Health, 2019, 19:1298 https://doi.org/10.1186/s12889-019-7646-8.

\section{Supplementary Files}


This is a list of supplementary files associated with this preprint. Click to download.

- STROBEchecklistFluorosis.doc 